\title{
CONGENITAL DEFECTS ASSOCIATED WITH PREMATURITY
}

\author{
BY \\ ALISON D. MCDONALD \\ From the Paediatric Research Unit, Guy's Hospital Medical School, London
}

(RECEIVED FOR PUBLICATION NOVEMBER 17, 1961)

Children who are premature in the sense that their birth weight is not more than $5 \frac{1}{2} \mathrm{lb}$. $(2.5 \mathrm{~kg}$.) are generally believed to have more mental and physical defects than heavier children. It has, however, seldom been possible to compare the prevalence of defects ascertained in a standard manner in children who are premature and those who are not. Neither is the relative prevalence of specific defects known according to gestational age, nor according to factors associated with prematurity such as surgical induction of labour and multiple birth. In a prospective study of maternal health in early pregnancy in relation to congenital defects in 3,179 children, there was an opportunity to compare the defects found in 204 premature children with those found in 2,975 children who were not premature and, although the sample of premature children was very small for this purpose, to examine the effect of gestational age, surgical induction of labour and multiple birth. A questionnaire had been completed at the mothers' first antenatal attendance, which included personal particulars, a brief obstetrical and medical history and a detailed account of illnesses and events during the first 12 weeks of pregnancy. A report on the infants was obtained within a few weeks of birth and later when they were between 3 and 6 years old. Details of this survey and its results are published elsewhere (McDonald, 1958; 1961). A brief account only is given below of the methods used in measuring the gestation period and in ascertaining defects in the children at 3 to 6 years of age.

At her first antenatal attendance the mother was carefully questioned about the date of her last menstrual period. When she was unable to give a date she was asked if possible to state a period of time within which it occurred. By this means it was possible to place all but three of the premature infants into two groups according to whether or not their stated period of gestation reached 36 weeks.

Defects in the children were ascertained in the following way. Reports were obtained from health visitors on a standard form for five-sixths of the children. Most of the rest had been clinically examined at school and for these the results of this examination were used; but in the case of a few children who had not yet had a school medical examination and for whom a health visitor's report was not obtained, reports were sought from mothers and general practitioners. The more serious defects. reported by health visitors were verified by reports from specialists. I examined personally children with suspected defects if a clinical report was not available or if they had any evidence of motor or mental retardation or deafness.

Of the 204 premature infants, 32 were stillborn, 23 died neonatally and 149 survived the first four weeks of life. One child died of leukaemia at 14 months. Reports were obtained on 142 of the 148 remaining children when they were between 3 and 6 years old. One of the six untraced children was known to have been adopted, two to have emigrated and three to have removed to an unknown address.

\section{Prevalence of Defects}

Of the 204 premature infants, $17(8 \%)$, of whom only one survived, had a gross malformation detected soon after birth (Table 1). The surviving child had a Fallot's tetralogy, and a tracheooesophageal fistula which was operated upon successfully. Among infants weighing over $5 \frac{1}{2} \mathrm{lb}$. $(2.5 \mathrm{~kg}$.), i.e. full-term, the prevalence of similar gross malformations was less than $1 \%$.

The prevalence among surviving premature children of various types of defect of both serious and minor significance compared with that in fullterm children is shown in Table 2. An excess was. found among the premature children of cerebral palsy $[2.9 \%$ compared with $0.1 \%(p=0.0003 *)]$, perceptive deafness of moderate degree $[0.7 \%$ compared with none $\left.\left(p=0.049^{*}\right)\right]$, serious eye defects [cataract $0.7 \%$ compared with none $(\mathrm{p}=0.049 *)$ ],

\footnotetext{
* Using 'exact' test for $2 \times 2$ tables.
} 
TABLE 1

SERIOUS DEFECTS AND SURVIVAL IN 198 PREMATURE INFANTS*

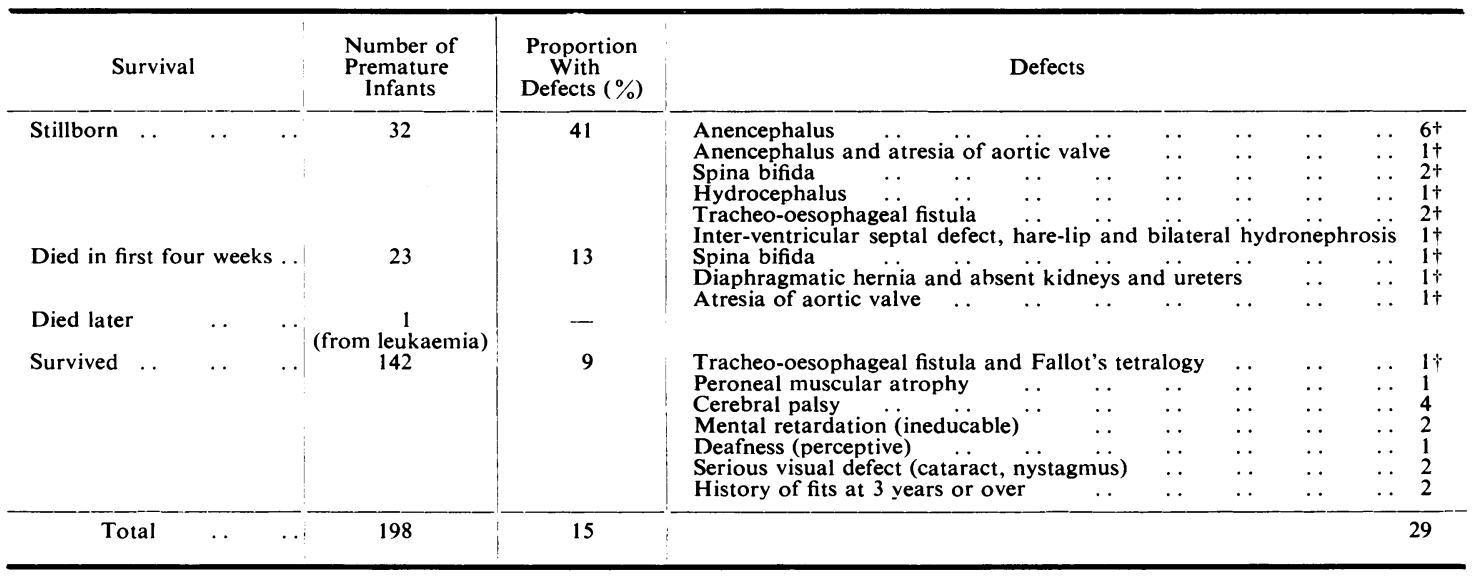

* Excluding six who were not traced at 3 to 6 years of age.

+ Defect detected soon after birth.

nystagmus $[0.7 \%$ compared with $0.04 \%$ ( $\mathrm{p}=$ $\left.0.095^{*}\right)$ ], and umbilical hernias [5\% compared with $\left.1 \cdot 2 \%\left(\mathrm{p}=0 \cdot 004^{*}\right)\right]$. The prevalence of mental retardation of such a degree that the children were

TABLE 2

PREVALENCE OF DEFECTS IN 140 SURVIVING PREMATURE CHILDREN† COMPARED WITH FULL-TERM CHILDREN

\begin{tabular}{|c|c|c|c|c|}
\hline \multirow{3}{*}{ Defect } & \multirow{3}{*}{$\begin{array}{l}\begin{array}{l}\text { Full- } \\
\text { term }\end{array} \\
(2,765)\end{array}$} & \multicolumn{3}{|c|}{ Premature } \\
\hline & & \multicolumn{3}{|c|}{ Gestation +} \\
\hline & & $\begin{array}{c}\text { All } \\
\text { Periods } \\
(140)\end{array}$ & $\begin{array}{c}36 \text { Weeks } \\
\text { and More } \\
(87)\end{array}$ & $\begin{array}{l}35 \text { Weeks } \\
\text { and Less } \\
(52)\end{array}$ \\
\hline & $\%$ & $\%$ & $\%$ & $\%$ \\
\hline Cerebral palsy ... & 0.1 & 2.9 & $2 \cdot 3$ & 3.9 \\
\hline Mental retardation $(a)$ & $0 \cdot 3$ & $1 \cdot 4$ & $1 \cdot 1$ & $1 \cdot 9$ \\
\hline Deafness .. .. .. & & 0.7 & - & 1.9 \\
\hline Visual defects: Severe $(b)$ & 0.04 & $1 \cdot 4$ & 二 & 3.9 \\
\hline Fits $(d)$ (i) Other $(c)$.. & $3 \cdot 8$ & $5 \cdot 7$ & $4 \cdot 6$ & $7 \cdot 7$ \\
\hline 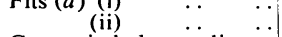 & $\begin{array}{l}1 \cdot 0 \\
1.5\end{array}$ & $2 \cdot 1$ & $\begin{array}{l}3 \cdot 4 \\
2 \cdot 3\end{array}$ & $\overline{1.9}$ \\
\hline Congenital heart disease & & & & \\
\hline Umbilical hernia .. & 0.5 & $\begin{array}{l}2 \cdot 1 \\
5.0\end{array}$ & $2 \cdot 2$ & $\begin{array}{l}1.9 \\
3.9\end{array}$ \\
\hline Inguinal hernia ... & $1 \cdot 3$ & 1.4 & $3 \cdot 1$ & 3.9 \\
\hline Asthma or eczema & $2 \cdot 6$ & $2 \cdot 9$ & $2 \cdot 3$ & $3 \cdot 9$ \\
\hline Musculo-skeletal defects & $1 \cdot 4$ & $1 \cdot 4$ & $1 \cdot 1$ & $1 \cdot 9$ \\
\hline Naevus $\ldots \quad \ldots \quad \ldots$ & $1 \cdot 0$ & $0 \cdot 7$ & & 1.9 \\
\hline
\end{tabular}

$\uparrow$ Fxcluding the following: one tracheo-oesophageal fistula and Fallot's tetralogy; one peroneal muscular atrophy; six untraced.

$\ddagger$ In one case the duration of gestation was unknown.

(a) Ineducable-excluding mongolism and cerebral palsy.

(b) Cataract, nystagmus.

(c) Squints, refractive errors.

(d) Fits: (i) One fit or more at 3 years or over or three or more episodes at under 3 years.

(ii) Not more than two episodes of fits at under 3 years.

(e) Including persistent systolic murmurs. considered ineducable was $1.4 \%$ in the premature group compared with $0.3 \%$ in the full-term group $(p=0.067)$. There was a small and not significant excess in the premature children of congenital heart defects (including persistent systolic murmurs), visual defects (squints and refractive errors) and a history of fits. The prevalence of other defects, such as inguinal hernia, musculo-skeletal abnormality and naevus, was similar in premature and full-term children, as was the prevalence of asthma or eczema.

\section{Relation Between Defects and Factors Associated with Prematurity}

The 17 infants in whom a serious morphological defect was discovered soon after birth, especially those with anencephalus, tended to have a lower birth weight than expected for their gestational age. This can be seen by comparing the two scatter diagrams (Figs. 1 and 2).

The prevalence of serious defects (Table 1) among the 142 surviving premature children traced was $9 \%$ compared with $2 \%$ in full-term children (difference/standard error $=2 \cdot 8$ ). Certain differences were found when the prevalence of serious defects in various groups of premature infants was compared, but none of these reached a $5 \%$ level of significance. None of the 24 children born after a surgically induced labour had a serious abnormality compared with $13(11 \%)$ children born after a labour of spontaneous onset. Two $(7 \%)$ of the 30 twins had serious defects compared with $11(12 \%)$ of the 94 single children (Table 3). Among children 


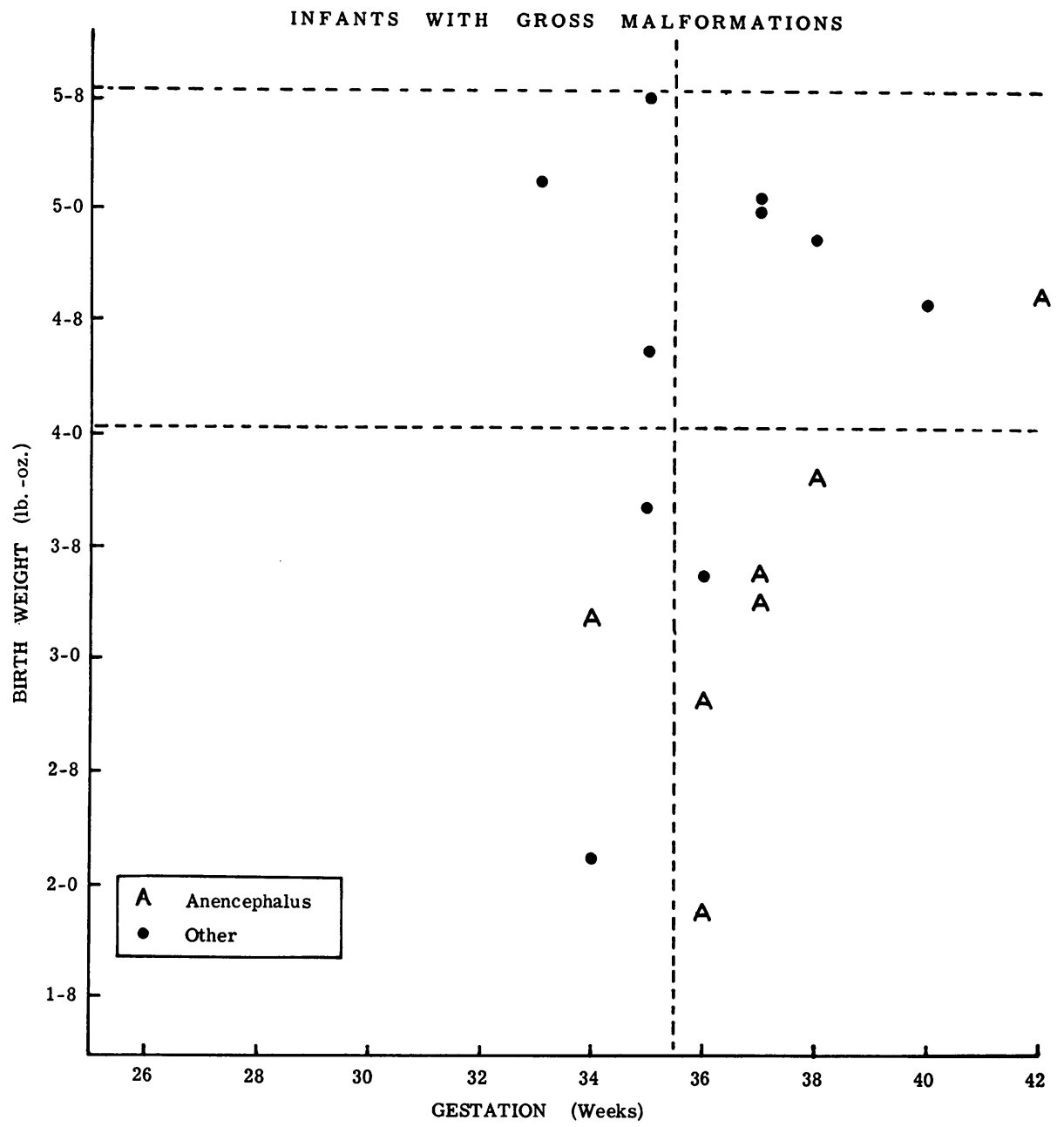

FIG. 1.-Infants with gross malformations according to birth weight and period of gestation.

whose gestational age was at least 36 weeks the prevalence was $7 \%$ compared with $13 \%$ in those of shorter gestational age. Only one $(7 \%)$ of the 15 children weighing not more than $4 \mathrm{lb} .(1 \cdot 8 \mathrm{~kg}$.) had a serious defect compared with $12(10 \%)$ of the 126 heavier children. The prevalence of serious defects found among the small premature infants must be considered in the light of their survival: $14(48 \%)$ of the 29 infants weighing not more than $4 \mathrm{lb} .(1 \cdot 8 \mathrm{~kg}$. $)$ had failed to survive the first weeks of life and $19(26 \%)$ of the 72 infants with a gestation period of less than 36 weeks had died during the first four weeks.

Certain defects found in surviving children are shown in Fig. 2 according to birth weight and period of gestation. There was no apparent tendency for these children to be light in relation to their period of gestation compared with children without defects. The serious defects of sight and hearing were found in children whose gestation period was less than 36 weeks. Cerebral palsy occurred in both shorter and longer gestation groups. In the longer gestation group there was a child with hemiplegia and one with bilateral athetosis probably due to rhesus iso-immunization, and in the shorter gestation group a child with hemiplegia and one with bilateral athetosis of unknown origin. Only one of the two children considered ineducable is shown on the diagram, but as the gestation period of the other was at least 40 weeks there was again no trend in relation to length of gestation. All children with a history of one or more fits had a gestation period 


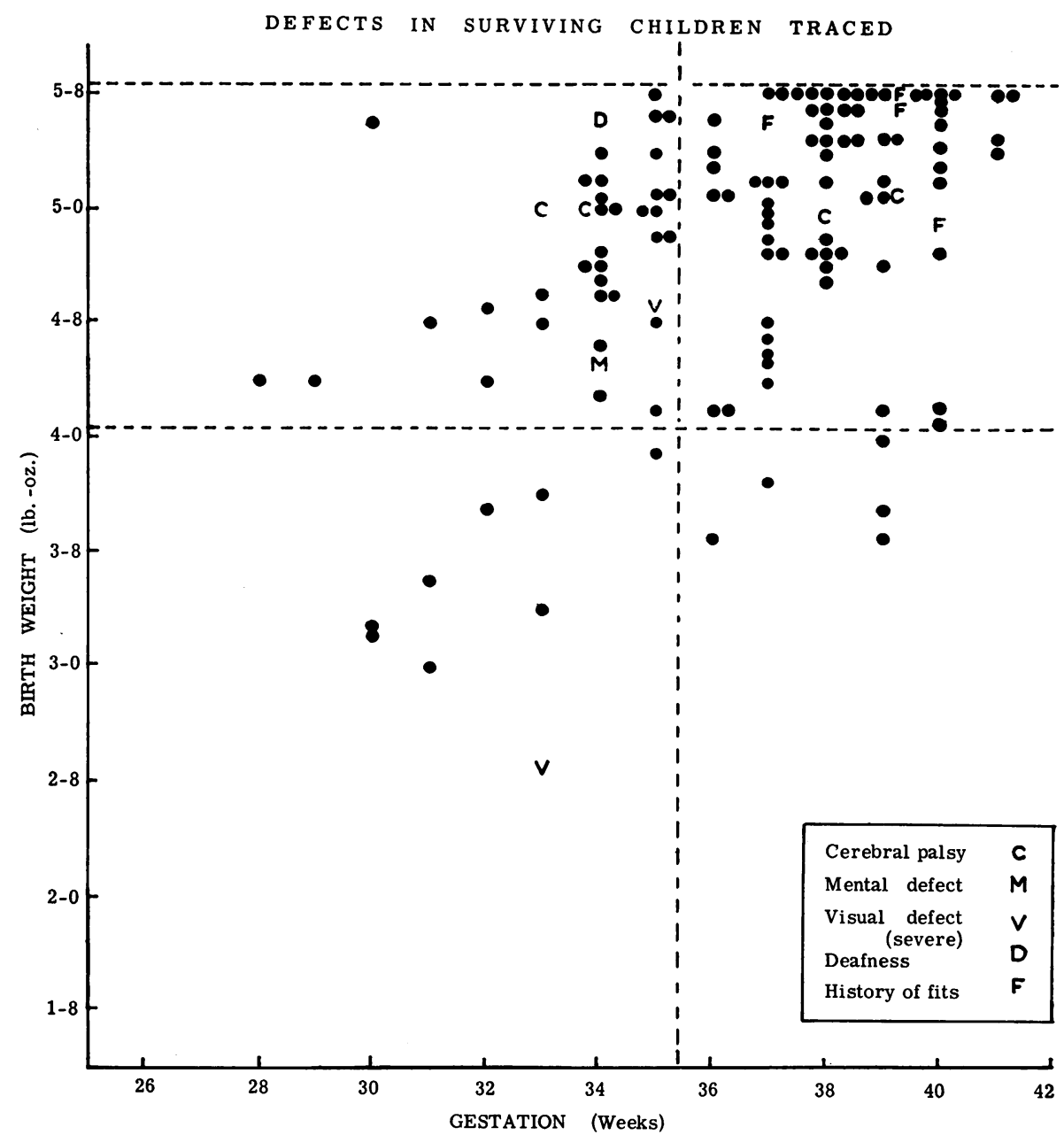

FIG 2.-Defects in surviving children traced, according to birth weight and period of gestation (excluding those for whom exact date of last menstrual period was not known).

TABLE 3

SERIOUS DEFECTS IN SURVIVING CHILDREN ACCORDING TO LENGTH OF GESTATION IN INDUCED AND SPONTANEOUS MULTIPLE AND SINGLE BIRTHS

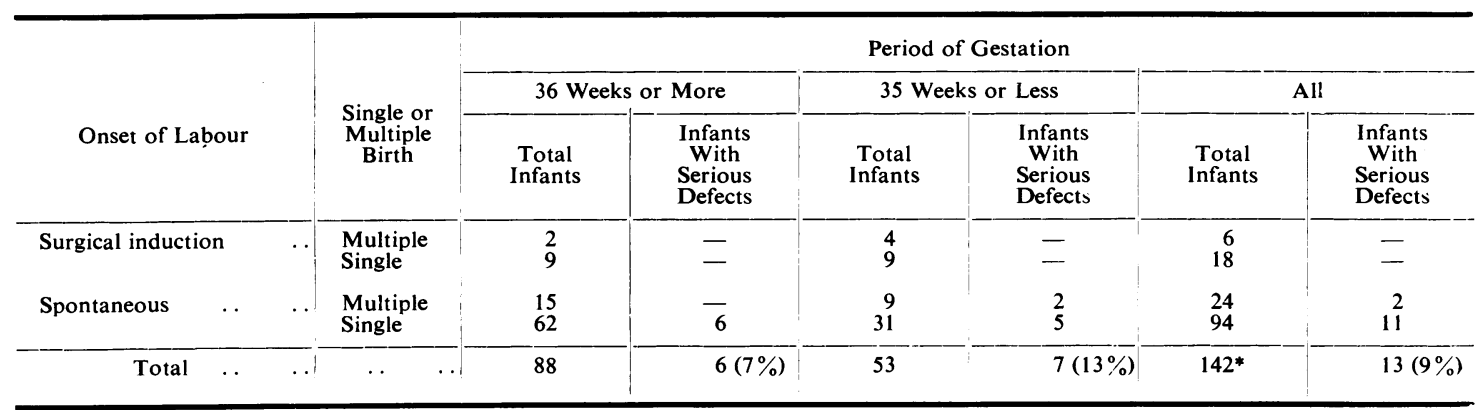

* Including one child of unknown gestational age. 
of 36 weeks or more as did most of the children with umbilical hernias.

\section{Discussion}

In view of the reasons given for failure to find the six untraced children, it is unlikely that they had serious defects. The prevalence of defects in the 3,179 children of all birth weights was about the same as in other series (McDonald, 1961). Therefore, although the sample of premature children is very small the prevalence of serious disorders among them is probably also a fair estimate.

It appears that infants with gross morphological defects (particularly the anencephalic foetuses with their deficit of cranium and nervous tissue) tend to fall into the premature group, not on the grounds of their gestational age, but because of their unduly low weight. This did not seem to be so with defects found later in the surviving children.

The prevalence of cerebral palsy in children of all birth weights was found to be $0 \cdot 29 \%$ and is similar to estimates ranging from 0.1 to $0.5 \%$ made by others. Cerebral palsy is known to occur more frequently in premature than in full-term children. Approximately half the children in most reported series of cerebral palsy are premature, and the same was found in this series. There was no case of spastic diplegia, a clinical type of cerebral palsy particularly associated with very low birth weight, but there were only 15 surviving children who did not weigh more than $4 \mathrm{lb} .(1 \cdot 8 \mathrm{~kg}$.), and the expected prevalence at this birth weight is about one in 20 (Ingram and Kerr, 1954).

Perceptive deafness is known to occur more commonly in premature than in full-term children. Drillien (1961) found a prevalence of deafness of approximately $4 \%$ among children weighing not more than $3 \mathrm{lb} .(1 \cdot 36 \mathrm{~kg}$.) at birth. Serious visual defects have also been found to be associated with low birth weight (Brown, 1960; Douglas and Mogford, 1953; Drillien, 1961).

Premature children have been found by various workers to have a raised prevalence of mental retardation (Alm, 1953; Asher and Roberts, 1949; Beskow, 1949; Drillien, 1959; Knobloch, Rider, Harper and Pasamanick, 1956). Cerebral palsy only accounts for some of this excess. Unless there is gross retardation, intellectual assessments made of children less than 6 years old may later prove incorrect. The prevalence of ineducability in the present series must therefore be regarded as only provisional, but the findings suggest that there was a slight excess not particularly associated with either short or long gestation periods.
Most of the umbilical hernias reported in the first few weeks of life had disappeared spontaneously by the age of 3 to 6 years, but the majority of those reported only at the age of 3 to 6 years had already been operated upon. The premature children had a raised prevalence of umbilical hernias reported both soon after birth and at 3 to 6 years of age. Consequently the excess of umbilical hernias found among them carried with it increased exposure to surgery and maternal separation.

\section{Summary}

In a series of 3,179 infants studied from the first antenatal attendance of their mothers, $204(6 \cdot 4 \%)$ weighed not more than $5 \frac{1}{2} \mathrm{lb} .(2 \cdot 5 \mathrm{~kg}$.) at birth. Of these, 149 survived the first four weeks of life; one child died at the age of 1 year, and $142(96 \%)$ were traced when they were between 3 and 6 years old.

Of the 142 surviving children, $13(9 \%)$ were found to have defects of a serious nature, compared with $2 \%$ in full-term children.

The prevalence of cerebral palsy, deafness, serious eye defects and umbilical hernia was significantly raised among the premature children.

There were children with serious defects among both multiple and single births following spontaneous labour, but none in a small group of births following surgically induced labour.

The severe defects of sight and hearing were in children with a gestation period of less than 36 weeks.

I am grateful to Professor P. Armitage for advising on, and to Miss I. Allen for carrying out, the 'exact' tests for $2 \times 2$ tables.

\section{REFERENCES}

Alm, I. (1953). The long-term prognosis for prematurely born children. A follow-up study of 999 premature boys born in wedlock and of 1,002 controls. Acta paediat. (Uppsala), 42, Suppl. 94.

Asher, C. and Roberts, J. A. F. (1949). A study on birthweight and intelligence. Brit. J. soc. Med., 3, 56.

Beskow, B. (1949). Mental disturbances in premature children at school age. Acta paediat. (Uppsala), 37, 125.

Brown, C A. (1960). Congenital abnormalities of the eye with particular reference to prematurity. Proc. roy. Soc. Med., $53,189$.

Douglas, J. W. B. and Mogford, C. (1953). Health of premature children from birth to four years. Brit. med.J., 1, 748 .

Drillien, C. M. (1959). Physical and mental handicap in the prematurely born. J. Obstet. Gynaec. Brit. Emp., 66, 721 .

(1961). The incidence of mental and physical handicaps in school-age children of very low birth weight. Pediatrics, 27,452 .

Ingram, T. T. S. and Kerr, J. D. (1954). The association of retrolental fibroplasia with cerebral diplegia. Arch. Dis. Childh., $29,282$.

Knobloch, H., Rider, R., Harper, P. and Pasamanick, B. (1956). Neuropsychiatric sequelae of prematurity; a longitudinal study. J. Amer. med. Ass., 161, 581 .

McDonald, A. D. (1958). Maternal health and congenital defecta prospective investigation. New Engl. J. Med., 258, 767. a prospective investigation. Maternal health in early pregnancy and congenital defect-final report on a prospective inquiry. Brit.J. prev. soc. Med., 15, 154. 